\title{
Processos, produtos e pessoas: o papel social do design e as relações de trabalho na indústria 4.0 sob a ótica dos serviços prestados por aplicativo
}

\author{
Raphael Jordão de Oliveira; \\ Camila Assis Peres Silva; \\ Juscelino de Farias Maribondo
}

\section{resumo:}

O presente artigo traz uma análise crítica acerca do impacto da indústria 4.0 sobre os processos industriais, sobre as pessoas em suas relações de trabalho e o consequente impacto no design de produtos. Para tanto, utilizamos como metodologia uma revisão da modificação histórica das relações de trabalho e os impactos da revolução industrial na formação do campo do design. Somado a isso realizamos levantamento da legislação vigente e iniciativas governamentais, bem como análise dos termos de serviço das principais empresas de aplicativos. Uma vez que o design de produtos é tanto resultado como agente transformador destas relações de trabalho, não há como discorrer sobre design social e, portanto, sustentável é discorrer sobre os direitos humanos do trabalho. Trazemos, portanto, essa discussão argumentando a importância de uma relação de trabalho sustentável. Concluímos a discussão apresentando o desafio da sustentabilidade diante das novas tecnologias introduzidas pela indústria 4.0.

\section{palavras-chave:}

Indústria; Sustentabilidade; Leis de Trabalho; Design 


\section{Introdução: Design para todos}

A sociedade atual vive a pós-modernidade ou modernidade líquida (BAUMAN, 1997), com suas relações e comportamentos fluidos. As novas tecnologias, em especial no que tange a comunicação, refletem tal fluidez, sendo impulsionadas pelos smartphones (LEMOS, 2007) e utilização de aplicativos (apps). Somado a isso temos o surgimento da indústria 4.0, que se utiliza das novas tecnologias e possui seu desenvolvimento aliado ao crescimento de sistemas físicos cibernéticos (ACATECH, 2013). Os impactos da indústria 4.0 têm afetado o mercado como um todo. Os mais visíveis atualmente são os serviços utilizados por meio de aplicativos. Tal como os pesquisadores Joana Contino e Alberto Cipiniuk, argumentamos que não há como discorrer sobre as práticas do Design sem considerar os contextos político, econômico e social (2018).

De forma a iniciar um debate acerca de tais transformações industriais trazemos um imagem que apresenta os quatro estágios da Revolução industrial, adaptado ao idioma português da Academia Alemã de Ciência e Engenharia (Deutsche Akademie der Technikwissenschaften, ACATECH). Como se observa nesse quadro, a quarta revolução industrial (indústria 4.0) "abrange novos conceitos de organização das atividades empresariais e inovações tecnológicas como fábricas inteligentes, sistemas ciberfísicos, internet das coisas e internet dos serviços" (CONTINO; CIPINIUK, 2018)

Figura 1 - Os quatro estágios da Revolução Industrial

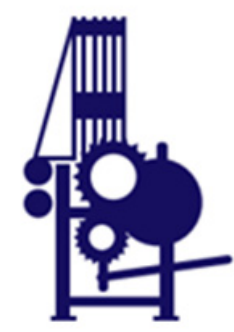

Primeiro tear mecânico 1784

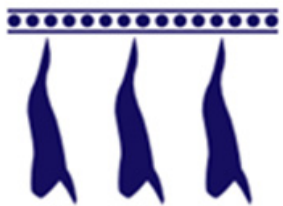

Primeira linha de produção, Matadouros de Cincinnati 1870

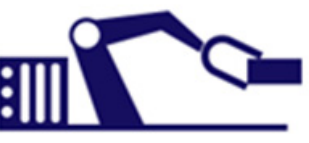

Primeiro controlador lógico programável (PLC), Modicon 084 1969

\section{4. revolução industrial} baseado em sistemas ciber-físicos

3. revolução industrial usa eletrônica e TI para obter maior automação da fabricação

2. revolução industrial segue a introdução da produção em massa movida a eletricidade com base na divisão do trabalho

1. revolução industrial segue a introdução de instalações de fabricação mecânica movidas a água e a vapor

Final do século 18

I

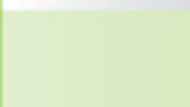


crescente preocupação com questões de sustentabilidade e usabilidades com produtos. O campo do design de interação tem papel fundamental neste cenário. "Um dos principais objetivos do design de interação é reduzir os aspectos negativos da experiência de usuário (p.ex., frustração, aborrecimento) e ao mesmo tempo melhorar os positivos (p.ex., divertimento, compromisso)" (PREECE; ROGERS; SHARP, 2013, p.2). Em outras palavras, o papel do designer é desenvolver produtos que promovam boa usabilidade e satisfação para todos os usuários.

As mudanças provocadas por essa mais recente revolução industrial põe a prova o papel de todas as profissões, tornando-as cada vez mais interdisciplinares. Ao que parece o grande beneficiado é o consumidor final. A ele é dado o acesso a bens não antes possíveis a um custo que ele pode pagar a história se repete de forma bem parecida a segunda revolução industrial no século 19. No que diz respeito ao designer no atendimento aos consumidores, é inegável a qualidade de atuação dos profissionais da área de interação e usabilidade. Eles vêm investindo na usabilidade com aplicativos, sendo o documentário Design Disruptors um bom exemplo da atuação desses profissionais, com o olhar centrado no usuário (2020). No entanto, em se tratando do design para aplicativos, há de se considerar que existem dois tipos de usuário: o que consome o serviço; e o que presta o serviço (a mão de obra trabalhadora).

Trazemos neste trabalho um debate que se fundamenta nas propostas de sustentabilidade estabelecidos pela Assembleia Geral das Nações Unidas, em especial no item 8 que define com um dos 17 objetivos o de "promover crescimento econômico sustentado, inclusivo e sustentável, emprego pleno e produtivo e trabalho decente para todos" (ONU, 2019). Nosso objetivo principal é questionar o papel social (e consequentemente sustentável) do design e sua relação interdisciplinar com o campo da sociologia e direitos humanos. A profissão surge "no entrecruzamento das críticas sociais e morais ao industrialismo que nasceram as primeiras propostas de fazer uso do design como agente de transformação" (CARDOSO, 2008, p. 76). É sua natureza ser crítico, ser social, ser para todos.

Para fomentar uma reflexão apresentamos neste artigo um paralelo entre a história do design e as modificações nas relações de trabalho frente à expansão industrial, destacando a contribuição do movimento britânico de Artes e Ofícios. Apresentamos ainda as modificações na Consolidação das Leis do Trabalho no Brasil sob o impacto da indústria 4.0. Finalizamos com uma provocação à reflexão de um design para todos sob a ótica dos direitos humanos.

\section{Um paralelo entre a história do design e a modificação das relações de trabalho frente à expansão industrial.}

Durante o fim do século 18 e início do século 19, houve a introdução das primeiras máquinas e ferramentas de precisão, com capacidade de reprodução em escala de peças e padrões. Essa mecanização trouxe o dilema da substituição da mão de obra, tendo persistido até início do século 20 . Sendo o período entre final do século 19 marcado na história do design pelo movimento de Artes e Ofícios liderado por William Morris (WILKES, 2015, p.26). Trata-se de um dilema muito próximo do que vivemos hoje com a indústria 4.0. O desaparecimento de funções antes existentes com o surgimento da máquina. Em nosso tempo o que se tem é o maior aperfeiçoamento do maquinário, podendo pôr fim a funções exercidas pelo homem. O professor Rafael Cardoso em sua Obra, "Uma introdução a História do Design", afirma:

(...) Segundo Andrew Ure e Charles Babbage, a grande meta da produção industrial seria a de retirar todo o processo de execução das mãos do trabalhador e entregá-lo para as máquinas, eliminando de vez o erro humano. Ambos acreditavam piamente que automação completa das fábricas estava preste a chegar e sua certeza acabou contagiando outros pensadores influentes como Karl Marx (...). (2008, p. 34).

Apesar de ainda estarmos em estágio inicial deste novo modelo de industrialização, os processos da indústria 4.0 podem ser mais claramente observados no setor de serviços. Os smartphones concorreram grandiosamente com a criação de diversas plataformas de prestação de serviços. Tais plataformas não detêm absolutamente nada. Não possuem o conhecimento técnico do que é oferecido, não possuem maquinário algum, apenas intermediam e cobram percentuais ou taxas pela intermediação dos serviços prestados. 
Surge então um novo modelo diverso daquele inicial, onde os aplicativos não são detentores dos meios de produção e também não possuem relação de trabalho com os indivíduos que prestam serviço em suas plataformas. Como mais adiante serão expostas, estas plataformas se autodenominam como intermediários do serviço servindo apenas como meio de pagamento digital. Essa modificação em relação à forma de trabalho foi identificada anteriormente por Karl Marx em sua obra "Crítica da economia política: Livro I: o processo de produção do capital”, onde narrou o início da Revolução Industrial e as consequências em relação à mão de obra. Vejamos:

(...) a transformação dos meios de produção individuais e dispersos em meios de produção socialmente concentrados e, por conseguinte, a transformação da propriedade nanica de muitos em propriedade gigantesca de poucos, portanto, a expropriação que despoja grande massa da população de sua própria terra e de seus próprios meios de subsistência e instrumentos de trabalho, essa terrível e dificultosa expropriação das massas populares, tudo isso constitui a pré-história do capital (...). (2013, p. 1011).

Karl Marx já apresentava, logicamente, sem usar o termo sustentabilidade, a importância da atenção à mão de obra. $\mathrm{O}$ design, campo técnico, que se dedica a projetar, tem sua atenção voltada $\mathrm{e}$ priorizada ao objeto ou produto final. Sua atenção em relação à sustentabilidade está focada, na maioria das vezes no produto, seu processo de fabricação, sua embalagem.

Durante a segunda Revolução Industrial, entre o final do século 18 e início do século 19 , observa-se uma desvalorização da mão de obra. Os interesses estavam voltados ao investimento em maquinário. A maior parte da mão de obra não necessitava de especialização técnica. Sendo dado destaque importante ao profissional que projetava (designer), com salário 3 a 5 vezes maior que os demais, visto que o projeto era parte essencial (CARDOSO, 2010) em relação à massa de trabalho que apenas operava o maquinário.

O estágio atual de quarta Revolução Industrial, chamado de Indústria 4.0, tende a desaparecer até mesmo com essa necessidade de mão de obra pouco especializada. Com alto investimento em maquinário e quase desaparecimento da necessidade de trabalhadores, as formas tradicionais de trabalho estão em curso de desaparecer (CELASCHI; DI LUCCHIO; IMBESI, 2017). O que demonstramos aqui é a essencialidade da mão de obra durante o processo de produção. Discorremos sobre o impacto do design sobre o capital humano. Bem como a importância de se considerar que tratar de sustentabilidade no design implica considerar a mão de obra empregada também usuária desses serviços.

\subsection{A contribuição do movimento de Artes e Ofícios na formação da profissão do Design}

O movimento britânico de Artes e Ofícios (em inglês Arts and Crafts) surgido no final do século 19 se caracterizou como uma reação ao impacto da revolução industrial à produção de bens de consumo. A reação proposta pelo movimento tem influências do pensamento medieval atrelado aos ideais da Igreja que naquele momento perdia espaço de controle social frente a uma classe burguesa crescente. Portanto, discutir a reação estética à industrialização significa considerar que o perfil do trabalhador era de um artista medieval que trabalhava em corporações e que cujo ofício era valorizado uma vez que este detinha total controle da técnica e do processo.

Em 1851, a $1^{\text {a }}$ Grande Exposição Universal sediada na Inglaterra - e com o intento de divulgar o poderio industrial do país - desencadeou posturas críticas que logo culminaram no movimento de Artes e Ofícios. De forma geral, a sociedade vivia um momento de euforia diante do avanço tecnológico sem precedentes. As engenhosas invenções supostamente vinham para facilitar e reduzir o trabalho dado ao artesão. No entanto, para os especialistas da arte a qualidade estética era questionável, "e logo surgiram na Inglaterra e em outros países debates sobre as razões de um fracasso tão patente" (PEVSNER, 2002, p.28). Vale ressaltar o que descreveu Nikolaus Pevsner:

Às alterações do pensamento europeu seguiam-se outras alterações no campo das ideias sociais, e assim o novo poder inventivo recebeu uma finalidade prática diferente. A ciência aplicada, como meio de governo do mundo, foi rapidamente 
incorporada num plano dirigido contra as classes que eram dominantes na Idade Média. A burguesia utilizou a indústria na sua luta contra a Igreja e a Nobreza, e a Revolução Francesa não fez mais do que concretizar aquilo que tinha vindo a ser lentamente preparado durante mais de dois séculos. O sistema medieval foi destruído, e com ele a classe de padrões cultos e ociosos e a classe dos artesãos cultos e formados pelas corporações. (2002, p.31).

Vários pensadores e artistas se destacaram na reação à máquina, na luta contra o "falso" e na renovação qualitativa do artesanato. O movimento, contudo, ganha força com o trabalho do multifacetado inglês William Morris (1834-1896). Ele lutava contra o que denominavam mau gosto estético, assim como contra a desumanização progressiva das condições de trabalho. Morris - artista e designer inglês, escritor e socialista - atuou na produção de desenhos, projetos para papel de parede, tapetes, mobiliário e tipografia, valorizando sempre as formas da natureza. Ele acreditava na importância de cada artesão, com suas habilidades em manufatura peculiares e profundo conhecimento do ofício. Seu trabalho influenciou não apenas os britânicos como se espalhou pela Europa, tendo chegado a América do Norte onde uma versão americana do movimento foi criada (WILKES, 2015, p. 26). Em termos de renovação estética o movimento teve grande influência sobre o que viria depois, Art Nouveau e os movimentos modernistas do início do século 20.

A contribuição do movimento de Arte e Ofícios reside na natureza multidisciplinar da oposição imposta à indústria. Existia não apenas uma oposição estética, mas também uma oposição intelectual, com denúncias a favor do meio ambiente (natureza) e de condições melhores para o trabalhador Existia também uma oposição política da aristocracia rural e da igreja que viam suas tradições ameaçadas, sendo a industrialização vista como ameaça ao bem-estar comum e aos valores mais elevados da sociedade.

Este movimento ilustra a estreita relação das artes e do design com questões intelectuais, políticas e sociais. De certo, as transformações na indústria no cenário atual são menos abruptas. As mudanças se concentram mais na esfera das relações de produção e consumo de produtos. Não há uma mudança de poderes e ascensão de classes tal como no período que marcou o fim da Idade Média. Tampouco, a qualidade estética com que se apresentam as grandes empresas de aplicativos é o cerne do problema. Tal como a euforia vivida na passagem do século 19 para 20, nossa sociedade tem celebrado as mudanças do século 20 e 21 a partir do advento da internet. Na medida em que os benefícios são maiores tendemos a desprezar os malefícios e a crítica perde força. A despeito disso, resgatamos a partir desse trabalho a importância de uma visão integradora do design. Seria capaz produzirmos aplicativos belos e exitosos sem corroborar para o ofuscamento de relações questionáveis de trabalho?

\subsection{A evolução das relações de trabalho da CLT a indústria 4.0 no Brasil.}

No Brasil, as relações de trabalho têm previsão legal na Consolidação da Lei do Trabalho (CLT) e na Constituição Federal. Essa proteção garantida ao trabalho vem sofrendo alterações ao longo dos anos devido às modificações na estrutura social. A CLT datada de 01 de maio de 1943, através do Decretolei $\mathrm{n}^{\mathrm{o}} 5.452 / 43$, celebrado pelo então presidente Getúlio Vargas, reuniu normas dispersas em uma "Consolidação". Essas normas foram alteradas ao longo dos anos e sua maior reforma e que trouxe maior distanciamento do texto original foi a lei $\mathrm{n}^{\circ} 13.467$, de 13 de julho de 2017 e neste ano de 2019, a edição da medida provisória $\mathrm{n}^{\circ} 881$ que ainda aguarda sanção ${ }^{1}$, alterou drasticamente as tradicionais formas de trabalho.

De maneira geral a CLT, criada em 1943, trazia com exclusividade apenas a contratação formal do empregado, com registro na Carteira de Trabalho e Previdência Social (CTPS). Ao longo dos anos algumas modificações e flexibilizações foram feitas, sendo a maior e mais impactante a introduzida pela Lei 13.467/2017. Esta mudança basicamente retira a força dos sindicatos, com medidas como tornar a contribuição sindical opcional. Bem como, reduz a atuação dos sindicatos retirando-lhes o poder de negociação coletiva passando a serem negociadas individualmente. Fixou teto para danos morais, reduziu intervalo intrajornada pela metade, criou regra para trabalho home

\footnotetext{
1 Medida Provisória no 881. Disponível em: https://www.congressonacional.leg.br/materias/medidas-provisorias/-/mpv/136531. Acesso em 19 set. 2019.
} 
office, criou a possibilidade de contratar autônomo que por sua condição afasta o vínculo empregatício e criou o trabalho intermitente.

É possível observar que houve supressão de representação sindical, e priorização dos acordos individuais de trabalho, também foi incluída a modalidade de trabalho Home Office, que antes era inexistente. Torna-se importante analisar que começa a haver retirada de representação coletiva, onde havia maior força dos trabalhadores, para aumento e priorização das relações individuais de trabalho. Consequentemente surgirão trabalhadores que para o mesmo serviço realizado terão salários e normas diversas criadas por situações pessoais que o empurram a aceitar condições de trabalho com menos benefícios.

É importante observar que surge a possibilidade de contratação de trabalhadores autônomos, na mesma modalidade de trabalho que antes apenas era possível com CTPS. Esta norma criada é verdadeira forma de burlar as leis trabalhistas. Foram inseridas a fim de retirar do empregador as obrigações trabalhistas que advém de um contrato formal de trabalho. Antes mesmo desta Reforma trabalhista da Lei 13.467/2017, outras flexibilizações já vinham ocorrendo em menor escala. Grande destaque merece a Lei do microempreendedor individual (LEI COMPLEMENTAR No 128, DE 19 DE DEZEMBRO DE 2008). Esta iniciativa do Governo Brasileiro de criação do Microempreendedor Individual (MEI) trouxe trabalhadores do mercado informal para a economia, com sua regularização e tributação, que antes era inexistente.

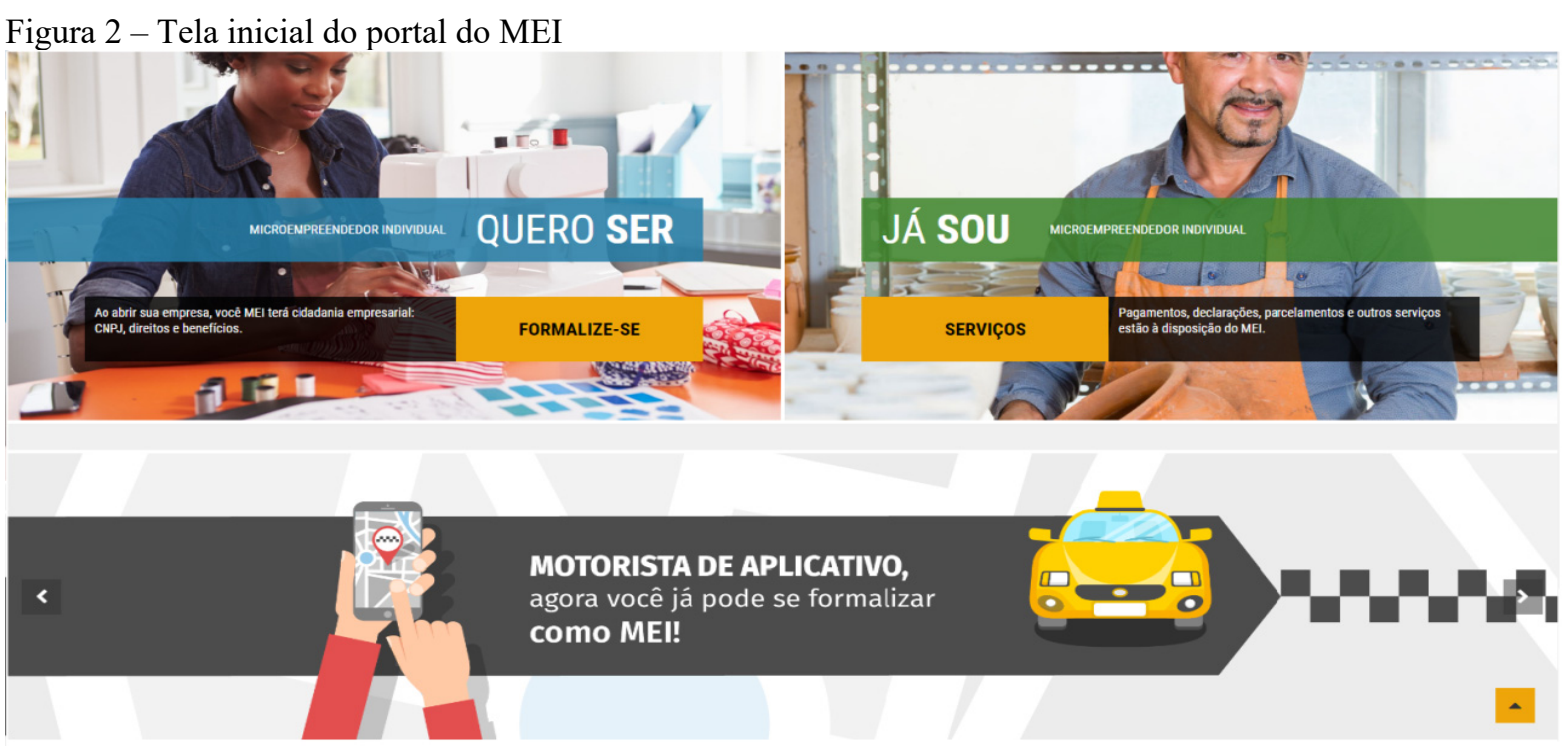

Fonte: Portal do Empreendedor (2019).

A criação do MEI trouxe a formalização de diversas atividades que antes eram tidas como paralelas, e não gozavam de qualquer benefício ou arcavam com contribuição físcal. O MEI trouxe benefícios como: 1)Auxílio maternidade; 2)Afastamento remunerado por problemas de saúde; 3) Aposentadoria; 4) Enquadramento no Simples Nacional (redução de tributos); 4) Cadastro Nacional de Pessoa Jurídica (CNPJ); 5) Cobertura pela Previdência Social; 6)Apoio técnico do SEBRAE.

Essas transformações e preocupação em realizar formalização de atividades que anteriormente eram tidas como informais, até mesmo os chamados "camelôs", passaram a ter atenção oficial, com tributação, regime de previdência e auxílio técnico. Essa formalização que anteriormente não existia cobria mudanças importantes na forma de trabalhar. Recentemente, com a chegada da Indústria 4.0, tecnologias de dispositivos móveis inovando em diversas formas de prestação de serviço, mais modalidades de trabalho antes inexistentes surgem e assim é preciso avaliar seu encaixe nos modelos de trabalho existentes ou se nova normatização deverá ser criada para atender modelos específicos de trabalho.

A Medida Provisória 881/2019, apelidada de MP da Liberdade Econômica, tenta em alguns pontos diminuir a burocratização e facilitar relações comerciais. O que se observa em um quadro mais amplo é que as formas de trabalho e relações econômicas mudaram desde a criação da CLT em 1943 até hoje tendo se passado 76 anos. É neste ponto que trabalhadores autônomos por intermédio de 
plataformas digitais prestam seus serviços. A forma como essa relação de trabalho se dá, será analisada mais adiante. Observar se tais mecanismos apesar de tecnologicamente atrativos respeitam o prestador de serviço. Verificar em que ponto a sustentabilidade ao pé das relações de trabalho se sustenta serviços de aplicativo.

\section{Design centrado no humano e os Direitos humanos do trabalho: uma reflexão orientada às mudanças sociais.}

É inquestionável a relação do design com as dinâmicas sociais e seu impacto na vida das pessoas. Com $\mathrm{o}$ advento das tecnologias da internet passamos a utilizar com mais frequência o termo design centrado no humano. No entanto, não é de hoje que essa preocupação vem sendo levantada. Como apresentado anteriormente, o movimento de Artes e Ofícios teve contribuição fundamental na formação da profissão, trazendo um olhar centrado no humano e nas relações de trabalho. Assim como a fundação da Bauhaus em 1919 na Alemanha, escola superior que marca o ensino do design moderno. A escola foi fundada por Walter Gropius que em seu manifesto "apelava para uma nova visão das artes, para a necessidade de uma interpretação integrada" (SOUZA, 2013, cap. 4, ed. Kindle).

Durante a construção do campo profissional tivemos autores engajados com o papel social do design. Para ilustrar destacamos o britânico Ken Garland que publicou em 1964 seu manifesto First Things First, o austro-americano Victor Papanek através de Design for the Real World publicado em 1971 e o brasileiro Joaquim Redig que em 1983 publicou sua obra Sentido do Design. Outros autores e profissionais não menos importantes seguem engajados com um olhar verdadeiramente ampliado para as funções do design. Afinal, "o design é uma manifestação da situação social, política e econômica, ou seja, o design está muito mais embasado numa relação com a sociedade do que somente apresentado como uma área de estudo que sustenta a si própria.(...)" (LIMA; MARTINS, 2011, p. 117)

A Declaração Universal dos Direitos Humanos (DUDH) em seu art. XXIII traz o reconhecimento do Trabalho como inerente à existência humana e abarca alguns pontos essenciais que merecem ser incluídos. São eles: livre escolha de emprego; condições justas e favoráveis de trabalho; proteção contra desemprego; igual remuneração por igual trabalho; remuneração justa e satisfatória; organizar-se em sindicatos e neles ingressar para proteção de seus interesses. Conforme apresentado inicialmente, esses direitos foram incluídos dentro dos objetivos para o crescimento sustentável, em que se resume o oitavo item em trabalho decente e crescimento econômico.

$\mathrm{Na}$ mesma direção, buscando mecanismos de sustentabilidade inseridos em empresas, e a fim de estimular práticas sustentáveis, foi criada a ISO26000, com suas normas e diretrizes estabelecidas pelo Instituto Nacional de Metrologia, Qualidade e Tecnologia (INMETRO), dentre elas diretrizes de responsabilidade social. Especial destaque está para os princípios de responsabilidade social da ISO26000, que aborda respeito aos direitos Humanos, o que nos torna a levar em conta novamente a importância das relações de emprego em questões sustentáveis principalmente sob a ótica humana da relação.

É importante observar as relações de trabalho criadas pelas indústrias 4.0. A partir delas, se criaram modalidades de trabalho em que existe um prestador de serviço, que media a entrega de algo ou transporta um passageiro. Em alguns casos até mesmo a contratação de um serviço autônomo, sem vínculo formal de emprego CLT, como exposto no quadro a seguir. Iniciativas como MEI criam novas formas de inclusão para novas modalidades de trabalho, a fim de entregar alguma espécie de salvaguarda por meio da Previdência Social. Realizando uma busca nos termos de aceite de serviços da Indústria 4.0 mais populares encontramos os seguintes pontos nos termos de uso do prestador de serviço:

Quadro 1 - Comparativo entre termos de uso

\begin{tabular}{|l|l|l|l|}
\hline Tema & Uber & IFood & 99 táxi \\
\hline $\begin{array}{l}\text { Relação de } \\
\text { trabalho }\end{array}$ & $\begin{array}{l}\text { Informa nos termos de } \\
\text { usuário item 2: "todos esses } \\
\text { serviços de transporte ou } \\
\text { logística são prestados por }\end{array}$ & $\begin{array}{l}\text { Em seu item 1.3 informa } \\
\text { que: "relaciona apenas à } \\
\text { intermediação (com } \\
\text { opção de pagamento on- }\end{array}$ & $\begin{array}{l}\text { Cláusula 4.8: } \\
\text { inexistência de relação } \\
\text { de trabalho }\end{array}$ \\
\hline
\end{tabular}




\begin{tabular}{|l|l|l|l|}
\hline & $\begin{array}{l}\text { prestadores terceiros } \\
\text { independentes que não são } \\
\text { empregados(as) e nem } \\
\text { representantes da Uber, nem } \\
\text { de qualquer de suas } \\
\text { afiliadas." }\end{array}$ & $\begin{array}{l}\text { line) para } \\
\text { comercialização de } \\
\text { produtos alimentícios" }\end{array}$ & \\
\hline
\end{tabular}

Fonte: UBER (2019); IFOOD (2019); 99TÁXI (2019).

Como se observa nenhum dos serviços apresentados acima sequer demonstra ou assume ter qualquer relação de emprego ou trabalho, excluindo, portanto, segundo o termo de uso dos mesmos qualquer responsabilidade por despesas de um possível vínculo empregatício e até mesmo da responsabilidade civil por danos causados por estes prestadores de serviço. Ressaltamos que as plataformas de aplicativo, são o que em primeiro momento surgiu juntamente com a indústria 4.0. Essa tecnologia de personalização do serviço entregue, em determinado momento despersonaliza o prestador de serviço, e ainda tenta desconectar o serviço prestado de sua vinculação as leis do trabalho.

Conforme demonstrado, o ponto que toca a sustentabilidade e as relações de trabalho visa justamente o respeito e a dignidade com que o trabalhador é tratado. O não respeito a normas básicas de Direitos Humanos, bem como a não atenção ao objetivo 8 da ONU para o crescimento sustentável é justamente o que se pretende questionar. Nenhuma das plataformas apresentadas se confrontadas a metodologia da ISO26000 obteria sua aprovação.

É de suma importância destacar que as condições justas e favoráveis de trabalho são uma garantia insculpida na Declaração Universal dos Direitos Humanos. Em diversos períodos podemos observar reclamações de trabalhadores destas plataformas em relação ao tratamento que recebem, bem como sua remuneração, vejamos:

1. Quase um terço dos motoristas do Uber está perdendo dinheiro, diz estudo. “(...) Um estudo feito nos EUA mostra que 30\% dos motoristas do Uber estão perdendo dinheiro quando os gastos com o carro são levados em conta. A pesquisa, feita com 1.100 motoristas, é do Instituto de Tecnologia de Massachusetts, o renomado MIT, um dos principais centros de pesquisa dos Estados Unidos. Segundo a pesquisa, quase três quartos dos motoristas do Uber nos EUA ganham menos do que um salário mínimo. O faturamento médio, sem contar impostos, é de US\$ 3,37 por hora de trabalho(...)"2

2. Motoristas do Uber protestam em frente à Bolsa de Valores. “(...) Também houve manifestações em frente ao escritório do Uber na capital fluminense. Além de aumentar o preço da corrida, os motoristas reivindicam redução no valor cobrado pelo Uber aos motoristas, que vai de $25 \%$ a $40 \%$, lugares para estacionamento e redução no preço dos combustíveis. (...) Quando começamos a trabalhar, tínhamos convênios com postos para baratear o preço da gasolina. Hoje, isso já não existe e pesa muito no que a gente ganha. Quando comecei, eu só fazia Uber, hoje, trabalho em mais dois aplicativos", reclama um motorista de Porto Alegre que preferiu não ser identificado na reportagem.(...)"3

3. Jornalista virou Uber por um mês e lucrou só 30 reais por dia. Replicaremos o seguinte trecho: “(...) A imagem do motorista competente e prestativo, que oferece água e bala de hortelã, está ficando para trás. Foi substituída por pessoas que, para não

\footnotetext{
${ }^{2}$ UOL. Disponível em https://www.uol.com.br/tilt/noticias/redacao/2018/03/03/quase-um-terco-dos-motoristasdo-uber-estao-perdendo-dinheiro-diz-estudo.htm. Acesso em 27 set. 2019

${ }^{3}$ DESTAK. Disponível em https://www.destakjornal.com.br/seu-valor/empresas---negocios/detalhe/motoristasde-uber-protestam-em-frente-a-bolsa-de-valores. Acesso em 27 de set. 2019
} 
ficarem no prejuízo, dirigem à exaustão, fazem plantão de doze horas, abordam clientes nas calçadas e chegam a organizar cartéis.(...)"4

Como se observa nos depoimentos dos trabalhadores de aplicativos se verifica a repetição das condições de trabalho da primeira e segunda revolução industrial. Ou seja, reduz-se a condição do trabalho a mera troca econômica, sem considerar que o trabalho descente para todas e todos é um dos objetivos da ONU para o crescimento sustentável..

\section{Considerações finais.}

As empresas são as principais fontes de criação de riqueza da economia, e, portanto a sustentabilidade passa inevitavelmente por este agente econômico. Sem sua colaboração é inviável qualquer tentativa de manter uma economia sustentável (BANSAL, 2002). Maneiras éticas e transparentes de fazer negócio têm sido conceituadas (VAN MARREWIJK, 2003). O termo sustentabilidade corporativa e responsabilidade social se confundem, tendo diversos conceitos diferentes, para o tema fíca difícil conceituar com objetividade o mesmo (GOBBELS, 2003). Alguns autores relatam que empresas passam a ter atividades sustentáveis ou aderir processos éticos, como maneira de ganhar legitimidade e serem reconhecidas como éticas legítimas e desejáveis (BANSAL, 2002; DRISCOLL; CROMBIE, 2001; PRAKASH, 1999, 2001).

Segundo o Fórum Econômico Mundial, "The Future of Jobs", a indústria 4.0 irá transformar os postos de trabalho, extinguindo assim 7,1 milhões de empregos, criando em contrapartida 2,1 milhões de novos empregos que demandarão alta especialização (Word Economic Forum, 2016). O design será beneficiado desta nova demanda de empregos de alta qualificação, com necessidades ligadas à criação de projetos. Decerto, uma "preocupação crucial do design de interação é desenvolver produtos interativos que sejam usáveis, o que genericamente significa produtos que sejam fáceis de aprender a usar, eficazes e que proporcionem ao usuário uma experiência agradável" (PREECE; ROGERS; SHARP, 2013, p.2). No entanto, trazemos uma inquietação para se pensar: Como designers podem explorar seu papel social dentro do universo da interação? Será possível que designers se envolvam de alguma forma em defesa de melhores relações de trabalho, tal como na época do movimento de Artes e Ofícios?

No clima econômico neoliberal de privatizações, fusões em nome da competitividade, demissões em massa e terceirização de funções especializadas, poucos designers podem sonhar com um emprego estável em uma grande empresa ou com a segurança de um contracheque ao final do mês e benefícios trabalhistas como férias e décimo terceiro. (CARDOSO, 2000, p.251).

O que percebemos pelo que já foi demonstrado anteriormente, é que as tecnologias vêm extinguindo empregos, ou os tornando menos necessários, e por tal razão reduzindo drasticamente sua remuneração. Empresas que desejarem estar dentro dos objetivos de sustentabilidade, possuir responsabilidade social, devem se atentar a seus colaboradores, independente do regime em que a relação de trabalho ocorra. As revoluções nos processos trazidas pela Indústria 4.0, com inserção de novas tecnologias, irão mudar drasticamente as relações de emprego que conhecemos. A extinção de postos de trabalho se torna uma realidade. A história da segunda Revolução Industrial parece se repetir.

Apesar de existir legislação de proteção ao trabalho e Documentos Internacionais que reconhecem direitos dos trabalhadores, bem como a ONU ter em sua meta de desenvolvimento sustentável a necessidade de olhar para o trabalho de forma digna, as primeiras empresas nos moldes da indústria 4.0 já demonstram caminhar na direção contrária. Modelos sustentáveis em relação à força trabalhadora devem ser observados por aquelas empresas que desejam ser reconhecidas como éticas

\footnotetext{
${ }^{4}$ VEJA SÃO PAULO. Disponível em https://vejasp.abril.com.br/cidades/uber-teste-motorista-um-mes/. Acesso em 27 set. 2019
} 
legítimas e desejáveis. Os designers, no que tange sua atividade projetual de alta especialização, parecem ter um futuro junto à indústria 4.0 mais promissor do que outros ramos de trabalho.

Processes, products and people: the social role of design and labor relations in industry 4.0 from the perspective of services provided by application

\section{Abstract:}

This paper provides a critical analysis of the impact of industry 4.0 on industrial processes, on people in their work relationships and the consequent impact on product design. For that, we used as methodology a revision of the historical modification of work relations and the impacts of the industrial revolution in the formation of the design field. In addition to this, we carried out a survey of current legislation and government initiatives, as well as an analysis of the terms of service of the main application companies. Since product design is both a result and a transformative agent of these labor relations, there is no way to talk about social design and, therefore, sustainable is to talk about human rights at work. Therefore, we bring this discussion by arguing the importance of a sustainable working relationship. We concluded the discussion by presenting the challenge of sustainability in the face of new technologies introduced by industry 4.0 .

\section{Keywords:}

Industry; Sustainability; Labor laws; Design

\section{Referências bibliográficas}

99 TAXI. Termos de Uso Motorista. Disponível em: https://99app.com/legal/termos/motorista/. Acesso em 25 set. 2019.

ACATECH, National Academy of Science and Engineering. Recommendations for implementing the strategic initiative INDUSTRIE 4.0. 2013. Disponível em: https://www.acatech.de/wpcontent/uploads/2018/03/Final_report_Industrie_4.0_accessible.pdf. Acesso em 29 nov. 2019.

BANSAL, P. The Corporate Challenges of Sustainable Development. Academy of Management Executive, v. 16, n. 2, p. 122-131, 2002. http://dx.doi.org/10.5465/ AME.2002.7173572

BANSAL, P.; BOGNER, W. Deciding on ISO 14001: economics, institutions, and context. Long Range Planning, v. 35, n. 3, p. 269-290, 2002. http://dx.doi. org/10.1016/S0024-6301(02)00046-8

BAUMAN, Z. Modernidade Líquida. Rio de Janeiro: Jorge Zahar Editora, 1997.

BAUMAN, Z. 44 cartas do mundo líquido moderno. Edição eletrônica de 2011. Rio de Janeiro: Editora Zahar. ISBN: 978-85-378-0770-5.

BRASIL. LEI No 13.467, DE 13 DE JULHO DE 2017. Disponível em:

http://www.planalto.gov.br/ccivil_03/_ato2015-2018/2017/lei//13467.htm. Acesso em 29 ago. 2019.

BRASIL. DECRETO-LEI No 5.452, DE 10 DE MAIO DE 1943. Disponível em:

http://www.planalto.gov.br/ccivil_03/decreto-lei/del5452.htm. Acesso em 29 ago. 2019.

BRASIL. Microempreendedor individual. LEI COMPLEMENTAR No 128, DE 19 DE DEZEMBRO DE 2008. Disponível em: http://www.planalto.gov.br/ccivil_03/leis/LCP/Lcp128.htm Acesso em 18 set. 2019.

CARDOSO, Rafael. Uma Introdução à História do Design. São Paulo: Editora Edgard Blucher, 2008. 
CONTINO, Joana; CIPINIUK, Alberto. Indústria 4.0: organização do trabalho e indústria da moda, p. 4825-4838. In: Anais do $13^{\circ}$ Congresso Pesquisa e Desenvolvimento em Design (2018). São Paulo: Blucher, 2019. ISSN 2318-6968, DOI 10.5151/ped2018-6.1_ACO_04

CELASCHI, F.; DI LUCCHIO, L; IMBESI, L. Design e phigital production:progettare nell'era dell'industria 4.0. MD Journal. 2017. ISSN 2531-9477 [online], ISBN 978-88-85885-00-4 [print]

DESIGN Disruptors. Direção de Matt D'Avella. Co-direção: Jennifer Fineran. Nova Iorque: InVision, 2016. 1 vídeo (63 min.), son., color. Disponível em: https://www.designdisruptors.com/. Acesso em: 15 jul. 2020.

DESTAK. Disponível em https://www.destakjornal.com.br/seu-valor/empresas---

negocios/detalhe/motoristas-de-uber-protestam-em-frente-a-bolsa-de-valores. Acesso em 27 de set. 2019

DRISCOLL, C.; CROMBIE, A. Stakeholder Legitimacy Management and the Qualified Good Neighbor: the case of Nova Nada and JDI. Business and Society, v. 40, n. 4, p. 442-471, 2001. http://dx.doi. org/10.1177/000765030104000405.

EXAME. Carreira: você S/A. Disponível em: https://exame.abril.com.br/carreira/o-lado-sombrio-dotrabalho-para-aplicativos-e-como-e-pior-para-mulheres/. Acesso em: 19 set. 2019.

GOBBELS, M.; JAN, J. AA1000 and SA8000 Compared: A Systemic Comparison of Contemporary Accounability Standards. Managerial Auditing Journal, v. 18, n. 1, p. 54-58, 2003. http://dx.doi. org/10.1108/02686900310454246

IFOOD. Termos de serviço. Disponível em: https://www.ifood.com.br/termos. Acesso em 25 set. 2019.

LEE, N. The 411: Feature Phones Vs. Smartphones. Cnet.com, 2010. Disponível em: https://www.cnet.com/news/the-411-feature-phones-vs-smartphones/. Acesso em: 29 ago. 2019.

LEMOS, A. Cibercultura: tecnologia e vida social na cultura contemporânea. Porto Alegre: Sulina, 2013.

LEMOS, A. Cidade e mobilidade. Telefones celulares, funções pós-massivas e territórios informacionais. Revista Matrizes No. 1 Outubro, 2007.

LEMOS, A. Mídia Locativa e Territórios Informacionais. In ARANTES, P; SANTAELLA, L. (org.)

Estéticas Tecnológicas. São Paulo: Ed. PUC/SP, 2007.

LIMA, E. C.; MARTINS, B.Design Social, o herói de mil faces, como condição para atuação contemporânea. In: BRAGA, M. da C. (org.) $O$ papel social do design gráfico. São Paulo: Editora Senac São Paulo, 2011.p.115-136.

MARX, K. Crítica da economia política: Livro I: o processo de produção do capital. São Paulo: Editora Boitempo, 2013. ISBN 978-85-7559-321-9.

MEGGS, Philip B.; PURVIS, Alston W. História do Design Gráfico. São Paulo: Cosac e Naify, 2009. NAÇÕES Unidas. 17 Objetivos de Desenvolvimento Sustentável da ONU. Disponível em: https://nacoesunidas.org/conheca-os-novos-17-objetivos-de-desenvolvimento-sustentavel-daonu/amp/ Acesso em 19 set. 2019.

NAÇÕES Unidas. Declaração Universal dos Direitos do Homem. Disponível em: https://nacoesunidas.org/wp-content/uploads/2018/10/DUDH.pdf. Acesso em 24 set. 2019.

NORONHA, E. G. Informal, ilegal, injusto: percepções do mercado de trabalho no Brasil. Revista Brasileira de Ciências Sociais, v. 18, n. 53. Outubro 2003

Portal do Empreendedor. Disponível em: http://www.portaldoempreendedor.gov.br/. Acesso em 19 set. 2019.

PRAKASH, A. A new institutionalist perspective on ISO 14000 and responsible care. Business

Strategy and the Environment, v. 8, n. 5, p. 322-335, 1999.

http://dx.doi.org/10.1002/(SICI)1099- 0836(199911/12)8:63.0.CO;2-H 
PRAKASH, A. Why do firms adopt 'beyond compliance' environmental policies? Business Strategy and the Environment, v. 10, n. 5, p. 286-299, 2001. http:// dx.doi.org/10.1002/bse.305

PREECE, J.; ROGERS, Y.; SHARP, H.. Design de interação: além da interação homemcomputador. Porto Alegre: Bookman, 2013. Edição Kindle.

SOUZA, P. L. P. Notas para uma história do design. Teresópolis: Grupob 2AB, 2013. Kindle Edition.

UBER. Termos de uso. Disponível em: https://www.uber.com/pt-BR/legal/terms/br/. Acesso em 19 set. 2019.

UOL. Disponível em https://www.uol.com.br/tilt/noticias/redacao/2018/03/03/quase-um-terco-dosmotoristas-do-uber-estao-perdendo-dinheiro-diz-estudo.htm. Acesso em 27 set. 2019

VAN MARREWIJK, M. Concepts and Definitions of CSR and Corporate Sustainability: Between Agency and Communion. Journal of Business Ethics, v. 44, p. 95-105, 2003. http://dx.doi. org/10.1023/A:1023331212247

VEJA SÃO PAULO. Disponível em https://vejasp.abril.com.br/cidades/uber-teste-motorista-um-mes/. Acesso em 27 set. 2019

WILKES, A. (ed.) Design: the definitive visual history. London: Dorling Kindersley Limited, 2015. WORLD Economic Forum, "The Future of Jobs...", January 2016, p. 15. Disponível em: http://www3.weforum.org/docs/WEF_Future_of_Jobs.pdf. Acesso em 19 set. 2019. 